\title{
Analysis of common genetic mutations in a cohort of Sri Lankan children with salt wasting form of Congenital Adrenal Hyperplasia
}

\author{
Praveenan Somasundaram ${ }^{1}$, Asanka Sudeshini Hewage ${ }^{1}$, Kirikankanange Shamya Harshini de \\ Silva ${ }^{2}$, Kamani Hemamala Tennekoon ${ }^{1}$
}

\begin{abstract}
Introduction Steroid hydroxylase deficiency due to CYP21A2 gene mutation is the most common cause of Congenital Adrenal Hyperplasia (CAH). Mutation spectrum in Sri Lankan CAH patients has not been investigated adequately.

Objectives This study attempted to study the spectrum of mutations in CYP21A2 gene in 30 patients with salt wasting form of $\mathrm{CAH}$ in Sri Lanka.

Methods Allele specific polymerase chain reaction was carried out using mutation site specific primers for eight mutations (P30L, I2G, 8bp deletion, I172N, E6 cluster, V281L, Q318X and R356W) reported as frequently occurring in other populations.

Results Fourteen patients had homozygous mutations; six patients were compound heterozygotes as determined by investigating parents of the patients, one patient had a large gene deletion which was previously reported and the remaining patients had at least one heterozygous mutation. The following allele frequencies were observed for each mutation P30L - 10\%, I2G - 40\%, 8 bp-18.33\%, I172N - 3.33\%, E6 cluster - 5\%, Q318X $40 \%$ and R356W - 3.33\%. V281L mutation was not observed in the study cohort. DNA sequencing revealed a novel mutation G292S in one patient.
\end{abstract}

Conclusion This is the first report describing a broad spectrum of mutations in CYP21A2 gene in Sri Lankan patients with $\mathrm{CAH}$. Mutation frequencies did not vary from other ethnic groups reported around the world.

Ceylon Medical Journal 2020; 65: 95-104

DOI: http://doi.org/10.4038/cmj.v65i4.9280

\section{Introduction}

Congenital Adrenal Hyperplasia (CAH), an inherited condition disrupting synthesis of adrenal cortical hormones [1] affects one in 15,000-20,000 children worldwide [2]. Among the five enzymes required for cortisol synthesis, 21-hydroxylase $(21-\mathrm{OH})$ is the most commonly affected in CAH [1]. CYP21A2 gene coding for 21-hydroxylase is located on chromosome 6 and has 10 exons. It has a pseudogene (CYP21A1P) which is $98 \%$ homolo-gous to the normal gene located in close proximity [3]. Recombination events that occur between the normal gene and the pseudogene during meiosis, in view of high sequence homology, leads to a variety of mutations including point mutations, deletions, frameshift and intronic mutations [4]. Deficiency of 21-OH results in a wide range of clinical presentations, the classic salt wasting form which can sometimes be fatal, classic simple virilizing form which leads to genital ambiguity and non-classical form which is a milder form of the disease [5]. Salt wasting CAH is observed in approximately $75 \%$ of the classic CAH patients, making it the most frequent severe form of the disease [6]. Approximately 11 deleterious mutations have been reported in the coding region of the $C Y P 21 A 1 P$ gene [7]. Most of them arise due to either gene conversion from the pseudogene [1] or large deletions. Approximately $25-30 \%$ of disease causing genes are chimeric [8]. One of the most frequent mutations which cause splicing defects in CYP21A2 gene is I2G [9]. An 8bp deletion in exon 3 results in an inactive enzyme while cluster of 3 point mutations in exon 6 abolishes the enzyme activity [10]. Q318X and R356W mutations in exon 8 results in a truncated protein $[11,12]$ and affect the substrate binding site [10] respectively. I172N, a mutation in exon 4 may alter the hydrophobic region of the enzyme to a polar region weakening the interaction of the enzyme with endoplasmic reticulum [10]. P30L and V281L mutations in exons 1 and 7 respectively only alter the secondary structure of the protein with no severe impact on the protein [10]. Mutation spectrum of CAH patients is reported to sometimes vary depending on the ethnic group. We do not have sufficient data for Sri Lanka as only large gene deletions have been studied previously [13]. Therefore in this study several point mutations and the 8bp deletion were analysed among a cohort of CAH patients in Sri Lanka.

${ }^{1}$ Institute of Biochemistry, Molecular Biology and Biotechnology, University of Colombo,Sri Lanka, ${ }^{2}$ Department of Pediatrics, Faculty of Medicine, University of Colombo and Lady Ridgeway Hospital, Colombo, Sri Lanka.

Correspondence: SH, e-mail: <sudeshi@ibmbb.cmb.ac.Ik>. Received 06 August 2020 and revised version 01 November 2020 accepted 02 December 2020.

This is an open-access article distributed under the terms of the Creative Commons Attribution License, which permits unrestricted use, distribution, and reproduction in any medium, provided the original author and source are credited. 


\section{Methods}

\section{Patients}

Thirty patients from 28 families were recruited from the Lady Ridgeway Children's Hospital (LRH), Colombo, Sri Lanka. They had been admitted to the University Paediatric ward with dehydration, ambiguous genitalia (in female patients) and progressive pigmentation. Biochemical assays showed hyponatremia, hyperkalaemia, elevated levels of serum 17-hydroxyprogesterone and higher amounts of dehydro-epiandrosterone sulphate which confirmed the salt wasting form of CAH [14]. After obtaining informed consent from the parents, $2.5 \mathrm{~mL}$ of venous blood was collected from the patients into $5 \mathrm{~mL}$ EDTA coated tubes. Once the genetic analysis of the patients was completed, blood samples $(5 \mathrm{~mL})$ were also collected from the parents of the patients suspected to be compound heterozygotes. This study received ethical approval (EC-15-050) from the Ethics Review Committee, Faculty of Medicine, University of Colombo Sri Lanka.

\section{Molecular analysis}

DNA was extracted from whole blood and CYP21A2 gene was analyzed for eight mutations namely P30L, I2G, 8bp deletion, I172N, E6 Cluster, V281L, Q318X and R356W using Allele Specific PCR (ASPCR). Each chromosome was checked for all eight mutations. Representative samples were sequenced for the confirmation of ASPCR results. When patients were suspected to be compound heterozygotes their parents' DNA was also analysed.

\section{Allele Specific PCR}

Two PCR reactions were performed for each mutation site. One reaction with the normal primer to detect the normal allele and the second reaction with the mutation specific primer to detect the mutated allele. A common primer was used in the reverse or forward orientation with the normal and mutated type primer. The common primer amplified only the normal gene, not the pseudogene. Normal and mutated primers differed only by their 3' terminal which correspond to the specific allele. But the primers for 8bp deletion and E6 cluster mutations had high dissimilarity with their normal primers (Supplementary Table 1, Figure 1).

Polymerase Chain Reaction (PCR) amplification was performed using respective primers (IDT Integrated DNA technologies, Coravallee, Iowa, USA) in a final volume of $25 \mu \mathrm{l}$ containing $100 \mathrm{ng}$ genomic DNA and Green GoTaq ${ }^{\circledR}$ reaction buffer, $\mathrm{MgCl}_{2}$, dNTPs and $\mathrm{GoTaq}^{\circledR}$ Flexi DNA Polymerase (Promega ${ }^{2 \mathrm{M}}$ M8295 Corporation, Madison, WI, USA). Amounts of each component used varied for different primer sets. PCR reactions were performed in five steps which includes initial denaturation at $94^{\circ} \mathrm{C}$ for 5 minutes, followed by 30 cycles containing denaturation at $94^{\circ} \mathrm{C}$ for 1 minute, annealing at $60-70^{\circ} \mathrm{C}$ (depending on the primer) for 30 seconds, extension at $72^{\circ} \mathrm{C}$ for 1 minute and a final extension at $72^{\circ} \mathrm{C}$ for 5 minutes. Then the products were visualized through ethidium bromide stained agarose gel electrophoresis.

\section{DNA sequencing}

To confirm the reliability of the ASPCR results representative samples were subjected to sequencing of the specific allelic regions. The whole gene was sequenced to detect possible novel mutations in the patients who did not have any of the eight mutations tested. PCR reactions were performed and the products were purified using Wizard ${ }^{\circledR}$ SV Gel and PCR clean-up system (Promega). Sequencing was performed in Applied Biosystems ${ }^{\mathrm{TM}} 3500$ Dx series Genetic Analyzer using Big Dye ${ }^{\circledR}$ Terminator v3.1 Cycle Sequencing Kit (Thermo Fisher Scientific, Waltham, MA, USA). Along with some allele specific primers sequencing primers were used for sequencing depending on the exon/intron sequence of interest (Supplementary Table 2).

\section{In silico analyses}

Reference DNA sequence was downloaded from ensemble (accession number-ENSG00000231852) at https:/ /asia.ensembl.org/Homo_sapiens/Gene/Sequence?db =core;g=ENSG00000231852;r=6:32038265-32041670. Novel variants were identified by aligning the patient's gene sequence with the reference sequence in Bioedit software. To predict the effect of novel variants in the protein YASARA version 18.4.24 software foldx plugin was used. The structure of 21-Hydroxyalse enzyme was obtained from https://www.modelarchive.org/doi/10.5452/ ma-anifj [15]. Protein structure which will be generated due to the variations p.G292S and p.R103K were constructed using foldx command. Constructed protein structure and the reference protein structure were superimposed to identify the energy difference between them ( $\Delta \Delta \mathrm{G}$ value). If $\Delta \Delta \mathrm{G}>0$ then the mutation is destabilizing the protein and if $\Delta \Delta \mathrm{G}<0$ then the mutation is stabilizing the protein. (Energy differences such as $0.5 \mathrm{kcal} / \mathrm{mol}$ are negligible)

\section{Results}

Thirty patients from 28 families comprised of 20 females and 10 males. Majority (22) were Sinhalese in ethnicity. There were 3 and 5 patients of Tamil and Moor ethnicity respectively. Seven patients were off springs of consanguineous unions. Homozygous mutations were observed in thirteen patients (43.3\%), fourteen patients (46.6\%) had at least one heterozygous mutations (Table 1) and among them 10 had more than one heterozygous mutation suggesting compound heterozygosity. 
Table 1. Mutations detected in the patients tested

\begin{tabular}{|c|c|c|c|c|c|c|c|c|}
\hline Patient & P3OL & $I 2 G$ & $8 b p$ & $I 172 \mathrm{~N}$ & E6 cluster & $V 281 L$ & $Q 318 X$ & $R 356 \mathrm{~W}$ \\
\hline C001 & & Het & & & & & Het & \\
\hline C002 & & Het & & & & & & \\
\hline C003 & & Het & & & & & & Het \\
\hline C004 & & Het & & & & & & Het \\
\hline $\mathrm{C} 005^{* *}$ & Hom & Hom & Hom & & & & & \\
\hline C006 & & Hom & Hom & & & & & \\
\hline C007 & & Het & & & & & Het & \\
\hline \multicolumn{9}{|l|}{ C008 } \\
\hline \multicolumn{9}{|l|}{ С $009 * *$} \\
\hline \multicolumn{9}{|l|}{ С010 } \\
\hline C011 & & & & & & & Hom & \\
\hline C012 & Het & Het & Het & & & & Het & \\
\hline C013 & & & Het & & & & Het & \\
\hline C $014^{* *}$ & & & & & & & Hom & \\
\hline C015 & & & & & & & Het & \\
\hline C016 & & & & & & & Het & \\
\hline C017 & & Het & & & & & Het & \\
\hline C018 & Het & Het & & & & & Hom & \\
\hline C019 & & Het & & & & & Het & \\
\hline C020 & & Het & & & & & Het & \\
\hline C021 & & & & Hom & & & Het & \\
\hline C022 & & Het & Het & & & & Het & \\
\hline C023 & & Hom & & & Het & & & \\
\hline C024 & & Hom & Hom & & & & Het & \\
\hline $\mathrm{C} 025^{* *}$ & & Hom & & & & & Het & \\
\hline C026** & & Hom & & & & & Het & \\
\hline C027 & Hom & & & & & & Het & \\
\hline C028** & & & Hom & & & & Het & \\
\hline C029** & & & & & Hom & & & \\
\hline C030 & & & & & & & Het & \\
\hline
\end{tabular}

Het-Heterozygous; Hom-Homozygous mutated, **Off springs of consanguineous unions

Allele frequencies observed is given in Table 2. Sequencing results of the selected samples corroborated the ASPCR results as given in Figure 1.

Table 2. Allele frequencies of CAH patients

\begin{tabular}{lccccccc}
\hline Mutation & $P 30 L$ & $I 2 G$ & $8 b p$ del & I172N & E6 cl & $Q 318 X$ & $R 356 W$ \\
\hline Frequency & $8.33 \%$ & $40 \%$ & $18.33 \%$ & $3.3 \%$ & $5 \%$ & $40 \%$ & $3.3 \%$ \\
\hline
\end{tabular}




$$
\text { CAOCTCCTCCTOCAOACAAGCTOOTOTCTAOOAAC }
$$

$A / C->G \quad(12 G)$

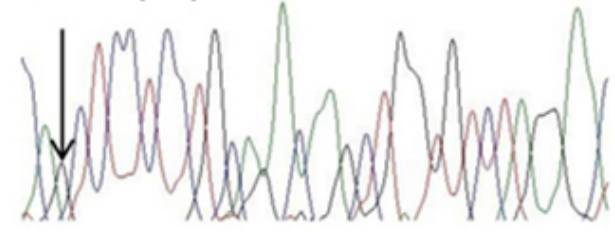

C A T C A A C T G T T A C C T C A C

T->A $(1172 \mathrm{~N})$
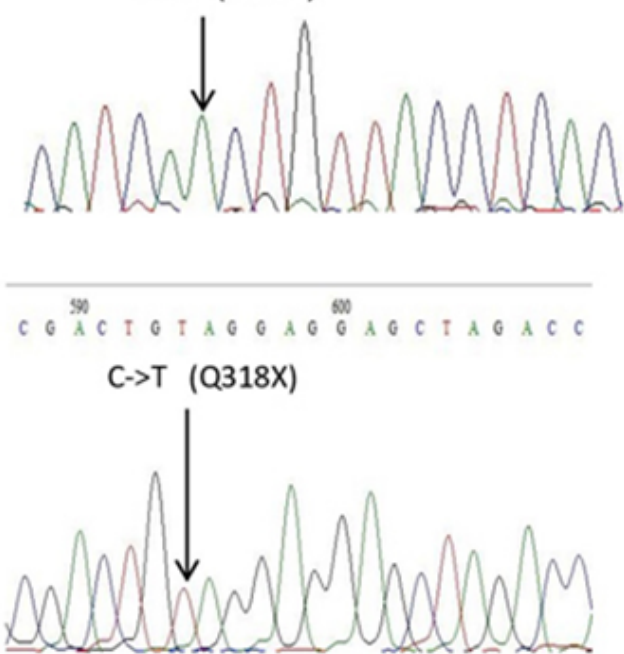
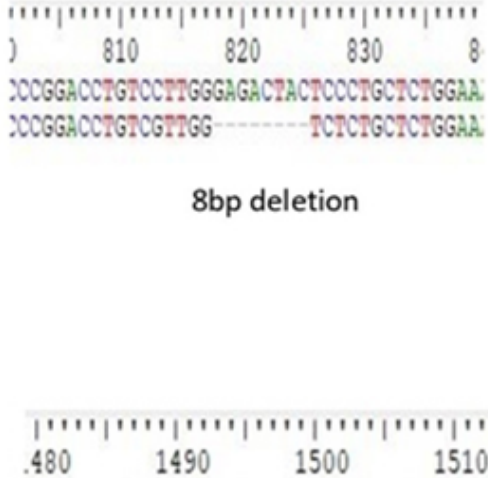

AGAGGGATCACATCGIGGAGATGCAGCTGAGGCl

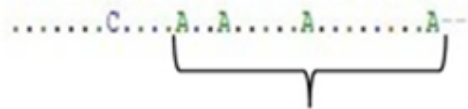

E6 Cluster

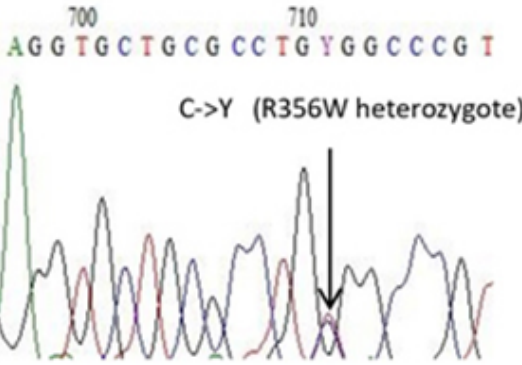

Figure 1. Electropherogram representing each mutation observed.

One of the remaining three patients had been previously detected to have a large gene deletion. Sequencing of the complete gene in the remaining two patients revealed two variants. One variant NC_000006. 12:g.32039109G>A in exon 3, which leads to amino acid substitution of p.R103K was observed patients C008 and C010. Second variant observed in patient C008 in exon 7 - NC_000006.12:g. 32040140G>A leads to amino acid substitution of p.G292S. When energy difference was calculated using foldX, $\Delta \Delta \mathrm{G}$ values of $0.274 \mathrm{kcal} / \mathrm{mol}$ and $2.290 \mathrm{kcal} / \mathrm{mol}$ were observed for R103K and G292S respectively suggesting that G292S will destabilize the 21 hydroxylase enzyme.

DNA sequencing also revealed the presence of chimeric gene. Patient C005 had pseudogene like sequence up to exon 3 and the remaining exons/introns had wild type CYP21A2 gene. Patient 29 had wild type gene sequence up to exon 4 and the subsequent introns and exons had pseudogene like sequence.

One or both parents were available for mutation testing in eight out of ten patients suspected to be compound heterozygotes. Table 3 shows results obtained. Figure 2 shows the results observed in family C012.

Table 3. Analysis of suspected compound heterozygous patients: heterozygous mutations observed in the patients and their parents, and predicted from parental analysis

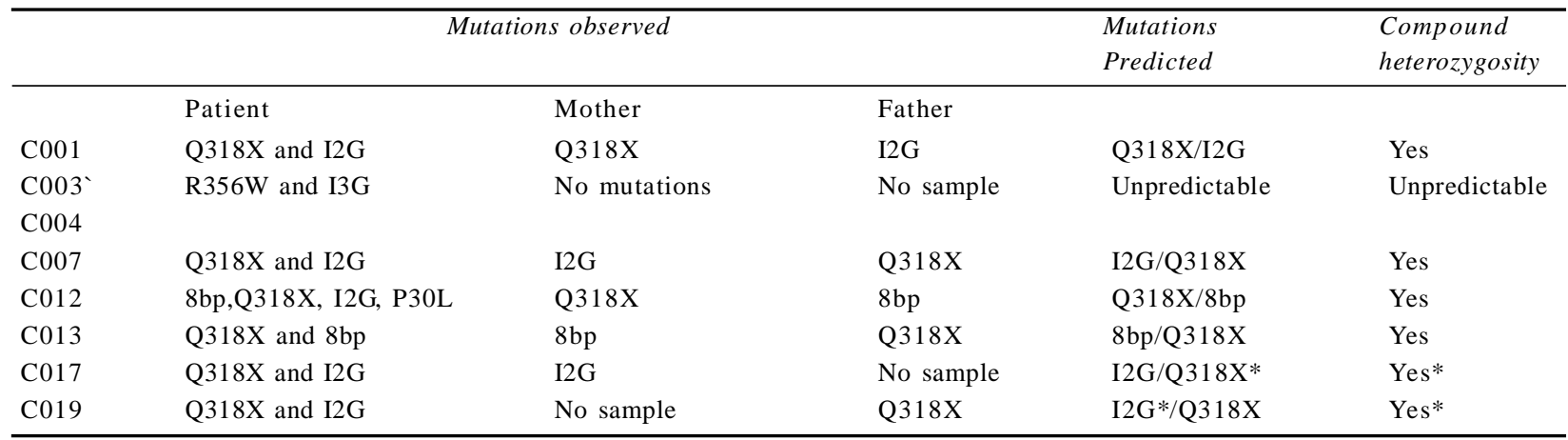

*Most likely to be heterozygous as the parent available for analysis carried one mutation, the other mutated allele is most likely to be inherited from the parent who was not tested. 


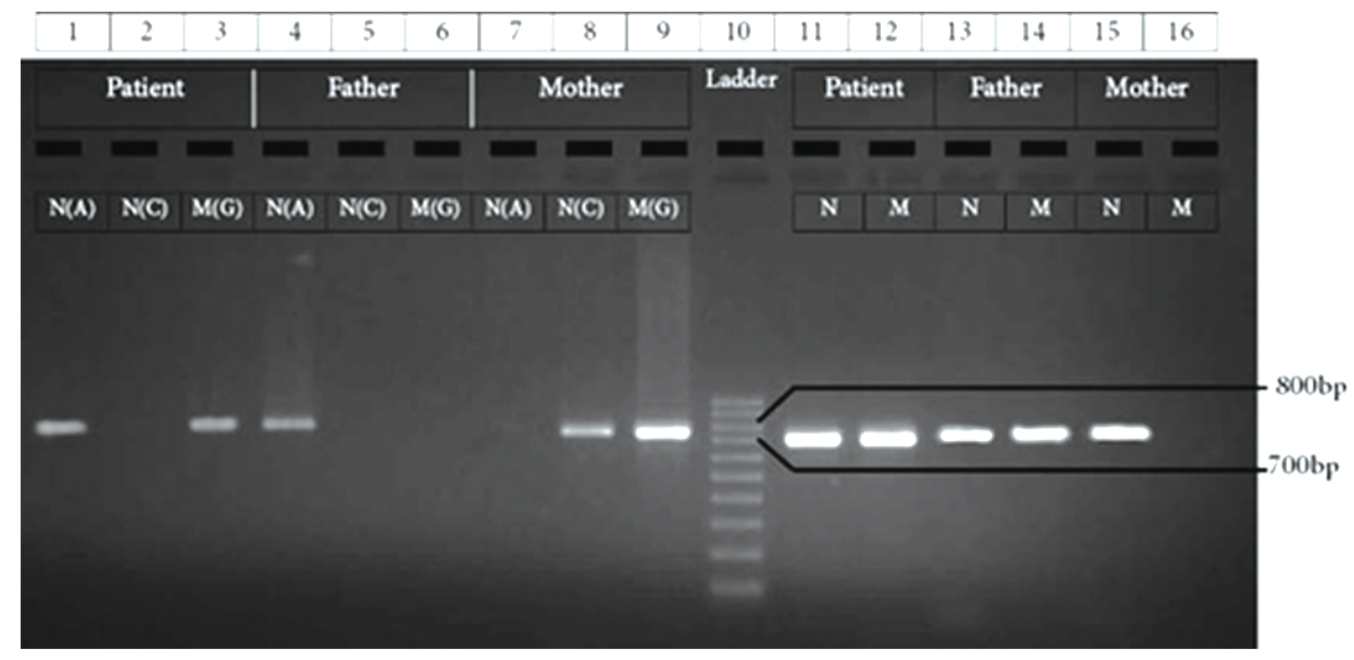

Figure 2. Allele Specific PCR results of family of patient C012.

Affected child was heterozygous for I2G and 8bp deletion. Mother was heterozygous for I2G and the father was heterozygous for 8bp deletion resulting in compound heterozygosity in the affected child.

\section{Discussion}

Thirty patients with salt wasting form of CAH in a Sri Lankan cohort were genotyped using allele specific PCR to find out the presence of eight common mutations in the CYP21A2 gene. When patients are suspected as compound heterozygotes their parent's samples were also analyzed by ASPCR. DNA sequencing was performed for the confirmation of ASPCR results and to investigate for possible novel mutations in two patients who did not carry any of the common mutations. This is the first study to report the spectrum of $C Y P 21 A 2$ mutations in $\mathrm{CAH}$ patients in Sri Lanka.

One of the most frequent mutations in our cohort was I2G with $40 \%$ of alleles having this aberration. Similar frequencies are reported from Hungary [16] and Japan [17]. Highest frequency (around 48\%) was observed in Mexico [18] and the lowest frequency (around 10\%) is in Argentina [19]. I2G mutation is usually associated with salt wasting form of $\mathrm{CAH}$.

We observed an allele frequency of $40 \%$ for Q318X. But only three patients (10\%) were homozygous. Six patients were compound heterozygotes. A much higher allele frequency (53\%) of Q318X mutation has been reported in Tabriz population [20] and a lower frequency of $35.5 \%$ and $25.7 \%$ from Tunisia and Brazil respectively. Only a few ethnic groups have higher frequency of Q318X allele, the reason for higher frequency in our cohort is unknown, may be it is due to a founder effect [21]. Further evidences are needed to prove this hypothesis.

Eleven alleles had 8bp deletion in exon 3 giving a prevalence of $18.33 \%$. 8bp deletion frequency was $13 \%$ in Iranian population [22], 12.7\% in an Indian cohort [23] and $12 \%$ in Romania [24]. Lowest allele frequencies were observed for the E6 cluster (5\%) and R356W (3.3\%) which are associated only with the salt wasting phenotype.

Only one patient had I172N mutation (homozygous mutation), but this mutation results in the simple virilizing form of CAH [25]. However this patient was also heterozygous for Q318X mutation which may have led to salt wasting phenotype. Patient C009 who was reported to carry a large genomic rearrangement in the $C Y P 21 A 2$ gene previously [13] was also included in the present study and PCR amplification failed with all the primers in this patient further confirming the large gene deletion.

Frequently $21 \mathrm{OH}$ deficiency occurs due to compound heterozygote genotype of the patient [2]. In our study ten patients were suspected as compound heterozygous. Analyses of their parents' DNA samples confirmed six patients to be compound heterozygous and for two patients parents' samples were not available. Among the confirmed compound heterozygous patients four patients had I2G/Q318X alleles, one patient had I2G/8bp alleles and one patient had 8bp/Q318X alleles.

Patients C003 and C004 were siblings and they both were heterozygous for the I2G and R356W mutations. Their mother did not carry either of these two alleles. Unfortunately father was not available for testing. Thus whether one or both mutations are of paternal or de novo in origin cannot be ascertained. Patients C025 and C026 were also siblings; and both were homozygous for I2G mutation and heterozygous for the Q318X mutation.

Consanguineous marriages increase the risk of genetic disorders because they share the common ancestors. In the present study the patients who were 
offspring of consanguineous marriages C005, C009 and C014 showed severe mutations. C005 had three homozygous mutations (I2G, 8bp deletion, P30L), C009 had a large gene deletion as previously reported [13] and C014 was homozygous for Q318X mutation. All these mutations will give rise to severe salt wasting form of $\mathrm{CAH}$.

Sequencing of the $C Y P 21 A 2$ gene showed the presence of chimeric genes in two patients. In patient $\mathrm{C} 005$ psuedogene sequences were observed up to exon 4 and after exon 4 normal gene sequences were observed, the pseudogene normal gene junction site was between end of intron 3 and exon 4 . This patient had 3 mutations (P30L, I2G \& 8b) as detected by ASPCR. In patient C029 normal gene sequence was observed up to exon 4 and pseudogene sequences thereafter with the junction within exon 4. In this patient PCR amplification failed. The common primers used in ASPCR were specific to the normal gene. But the ASPCR result was positive for primers of E6 cluster in which forward primer was normal gene specific while the reverse primers were allele specific. Here only the mutated allele specific primer produced a band which confirms the pseudogene sequences in this patient.

Sequencing results also revealed two novel variants; R103K and G292S. Patient C008 had both R103K and G292S which gives an energy difference of $2.290 \mathrm{kcal} / \mathrm{mol}$ suggesting that the mutations are destabilizing the protein. But patient C010 carried only R103K which gives an energy difference of $0.274 \mathrm{kcal} / \mathrm{mol}$ which will not have any impact on the protein.

In conclusion this is the first study which has provided the spectrum of genetic mutations in Sri Lankan CAH patients. The mutation spectrum was similar to what is reported for other ethnic groups around the world. Furthermore one novel pathogenic mutation was identified. The presence of two chimeric genes was a very unique finding as these have been reported only in a few ethnic groups. This study will lay the foundation for genetic testing and genetic counseling for CAH in Sri Lanka.

\section{Supplementary materials}
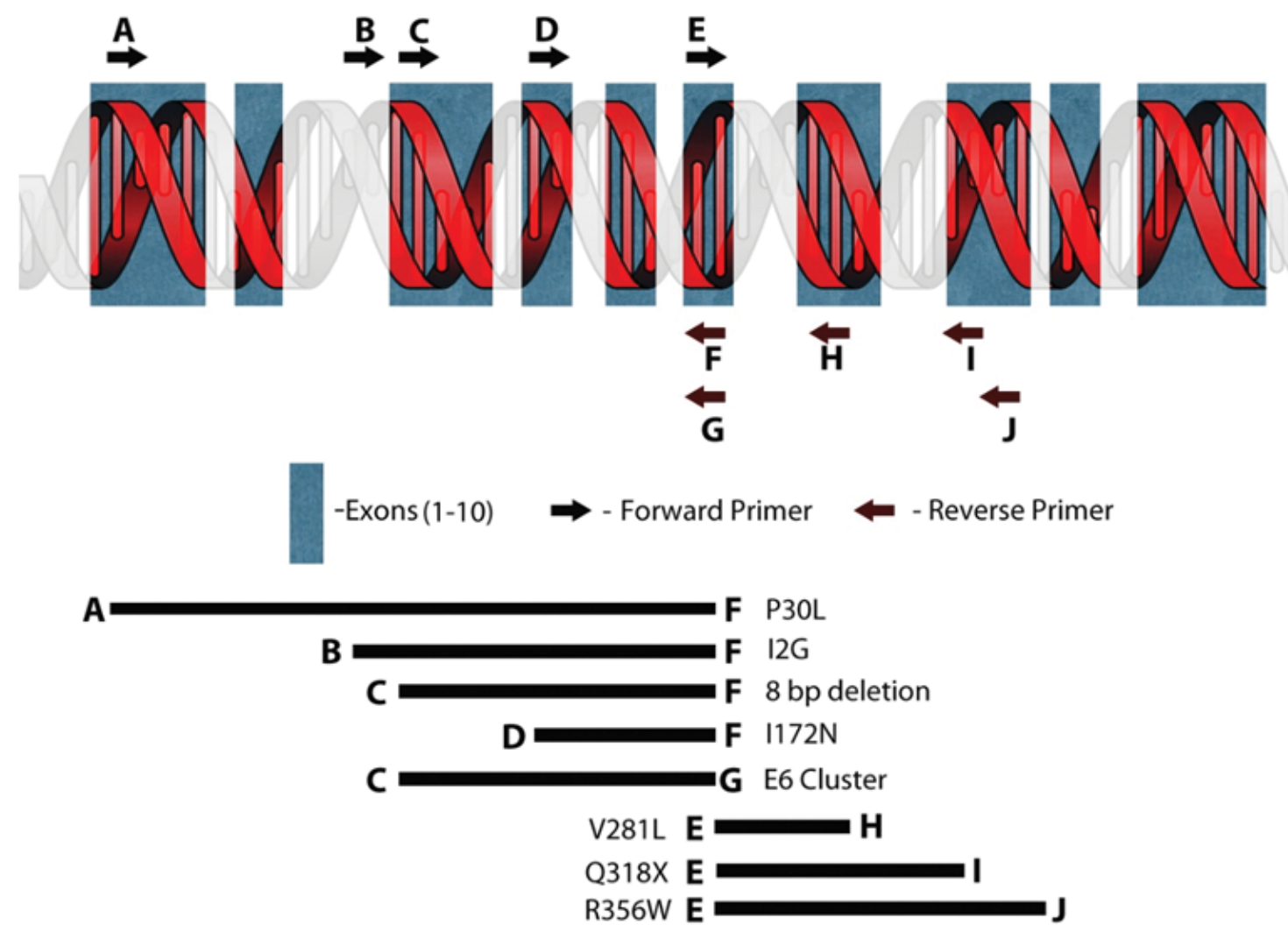

Supplementary Figure 1. Location of the primers used for allele specific PCR 


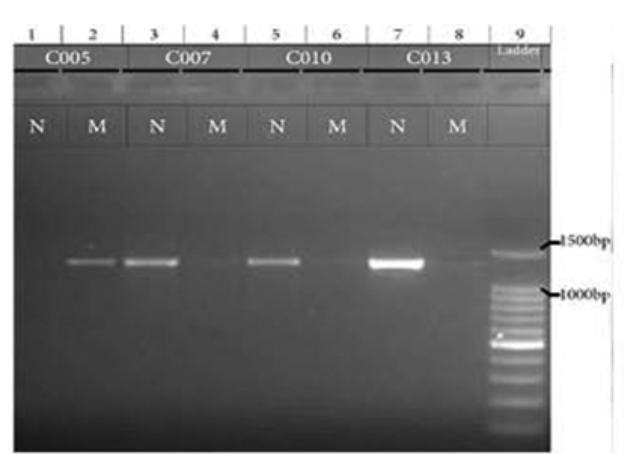

A) Exon 1 (P30L)

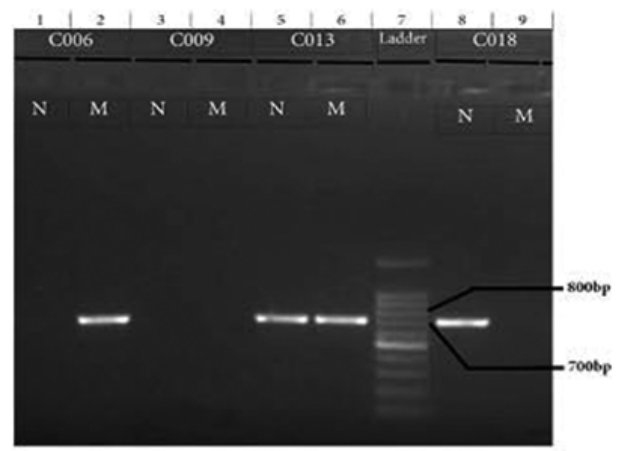

C) Exon 3 (8bp deletion)

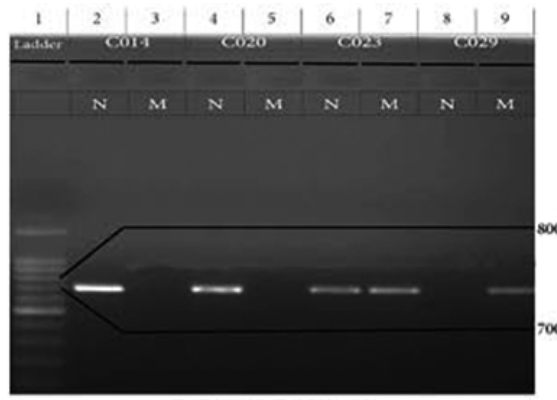

E) Exon 6 (E6 Cluster)

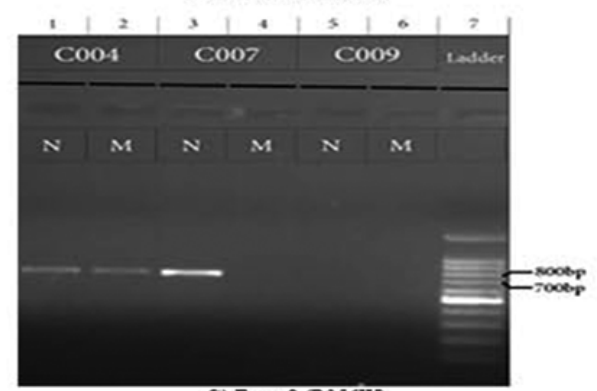

G) Exon 8 (R356W)

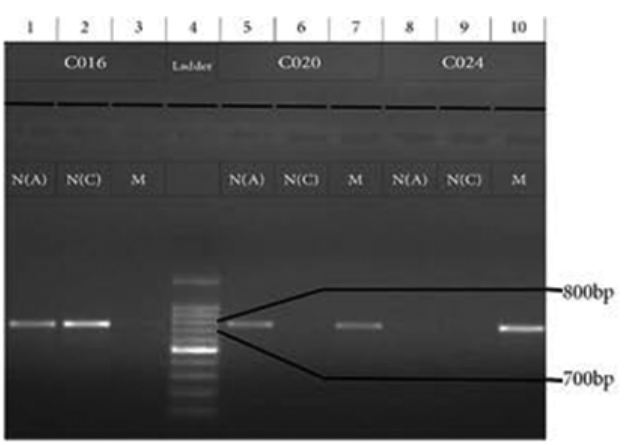

B) Intron 2 (I2G)

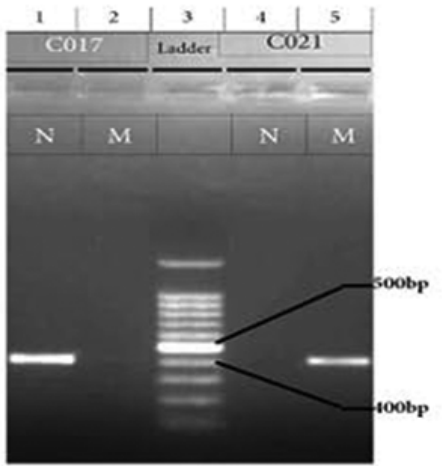

D) Exon 4 (1172N)

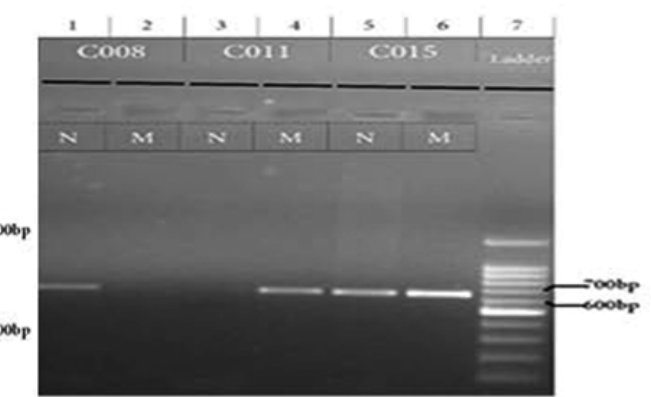

F) Exon $8(Q 318 X)$

Supplementary Figure 2. Representative allele specific PCR results for all 7 mutations observed in different samples. For each sample two reactions were performed one with the normal and the other with the mutated primer (Designated as $\mathrm{N}$ and $\mathrm{M}$ ). Depending on the product formation normal, heterozygous and homozygous mutations were determined. No bands were observed in sample C009 (shown in panel $C$ and $G$ ) perhaps due to the large gene deletion which was previously reported for the patient. 
In Figure 2, panel A shows P30L mutation results of samples C005,C007,C010 and C013. Since the product was formed only in N lane sample C010, C007 and C013 were wild type, sample C005 had product in M lane hence it is homozyogus mutated. Panel B depicts I2G mutation results of sample C016, C020 and C024. Since C016 has products only in $\mathrm{N}$ lanes it is wild type, $\mathrm{C} 020$ has products in both $\mathrm{N}$ and $\mathrm{M}$ lanes it is heterozygous mutated and $\mathrm{C} 024$ has product only in M lane it is homozygous mutated. Panel C shows the result of $8 \mathrm{bp}$ deletion results of sample C006,C009,C013 and C018. Sample C006 is homozygous mutated, C013 is heterozgous mutated and C018 is wild type. Panel D shows the I172N mutation results of sample C017 and C021. Sample C017 is wild type and C021 is homozyogus mutated. Panel E shows the E6 cluster mutation results of C014,C020,C023 and C029. Sample C014 and C020 are wild type, sample C023 is heterozygous mutated and sample C029 is homozygous mutated. Panel F shows the Q318X mutation results of C008,C011 and C015. Sample C008 is wildtype, sample C011 is homozyogus mutated and sample C015 is heterozyogus mutated. Panel G shows the R356W mutation results of sample C004,C007 and C009. Sample C004 is heterozygous mutated and sample C007 is wildtype.

\section{Supplementary Table 1. Primer sequences used in ASPCR}

\begin{tabular}{|c|c|c|c|c|c|c|}
\hline Mutation & & Forward primer & & Reverse primer & Size & $\begin{array}{l}\text { Annealing } \\
\text { temperature }\end{array}$ \\
\hline & $\mathrm{N}$ & 5’TCCGGAGCCTCCAССТССС & & & & \\
\hline \multirow[t]{3}{*}{ P30L } & & & & & 1326bp & $65.5^{\circ} \mathrm{C}$ \\
\hline & M & 5’TCCGGAGCCTCCACСТCСТ & & & & \\
\hline & $\mathrm{N}$ & 5’TТСССАСССТССАGСССССАА & & & & \\
\hline \multirow[t]{2}{*}{ I2G } & $\mathrm{N}$ & 5’ТTСССАСССТССАGСССССАС & $\mathrm{N}$ & 5’AGCTGCATCTCCACGATGTGA & $761 \mathrm{bp}$ & $66.7^{\circ} \mathrm{C}$ \\
\hline & M & 5’TTCССАСССТССАGСССССАG & & & & \\
\hline $8 \mathrm{bp}$ & $\mathrm{N}$ & 5'CGGACCTGTCCTTGGGAGACTAC & & & 704bp & $62.9^{\circ} \mathrm{C}$ \\
\hline \multirow[t]{2}{*}{ deletion } & M & 5’ACTACCCGGACCTGTCCTTGGTC & & & & \\
\hline & $\mathrm{N}$ & 5'TCСTCACCTGCAGCATCAT & & & 417bp & $61.1^{\circ} \mathrm{C}$ \\
\hline $\mathrm{I} 172 \mathrm{~N}$ & M & 5’СТСТССТСАССТGСAGCATCAA & & & & \\
\hline \multirow[t]{4}{*}{ E6 cluster } & $\mathrm{N}$ & 5'CGGACCTGTCCTTGGGAGACTA & & & 706bp & $65.7^{\circ} \mathrm{C}$ \\
\hline & & & M & 5’TCAGCTGCTTCTCCTCGTTGTG & & \\
\hline & & & $\mathrm{N}$ & 5'TCCACTGCAGCCATGTGCAC & & \\
\hline & & & & & 333bp & $64.3^{\circ} \mathrm{C}$ \\
\hline \multirow[t]{2}{*}{ V281L } & & & M & 5'TCCACTGCAGCCATGTGCAA & & \\
\hline & $\mathrm{N}$ & 5'GAGGGATCACATCGTGGAGATGCA & $\mathrm{N}$ & 5’TTCGTGGTCTAGCTCCTCCTG & & \\
\hline \multirow[t]{2}{*}{ Q318X } & & & M & 5'AGTTCGTGGTCTAGCTCCTCCTA & $647 \mathrm{bp}$ & $63.8^{\circ} \mathrm{C}$ \\
\hline & & & $\mathrm{N}$ & 5’CTAAGGGCACAACGGGCCG & & \\
\hline R356W & & & $\mathrm{M}$ & 5’CTAAGGGCACAACGGGCCA & $757 \mathrm{bp}$ & $67.1^{\circ} \mathrm{C}$ \\
\hline
\end{tabular}

Site of point mutations are indicated in Boldface. Underlined sequence in EX3NS shows the deleted 8bp sequence of CYP21A2 gene. $\mathrm{N}=$ Normal and $\mathrm{M}=$ Mutant. 
Supplementary Table 2. Primers used for sequencing

\begin{tabular}{crr}
\hline Primer & Sequence & Position \\
\hline 1F & 5'-TCGGTGGGAGGGTACCTGAA-3’ & nt -122 to -103 \\
2R & 5'-GGGAACTGATGAAGGCAGCT-3’ nt $753-734$ \\
3R & 5'-TCCAGAGCAGGGAGTAGTCTC-3' nt $840-821$ \\
\hline
\end{tabular}

\section{Acknowledgments}

We thank all the patients and their parents who participated in this study, staff of Ward 1, Lady Ridgeway Children's Hospital, Colombo for clinical assistance, Ms M Jayasundera and Dr. D Jayathilake for assistance in sample collection from patients and staff of the Institute of Biochemistry, Molecular Biology and Biotechnology, University of Colombo for various assistance.

\section{Source of support}

This work was supported by the Institute of Biochemistry Molecular Biology and Biotechnology and constituted a part of MSc studies of Praveenan Somasundaram.

\section{Conflicts of interest}

The authors declare no conflicts of interest.

\section{References}

1. Speiser PW, White PC. Congenital adrenal hyperplasia. $N$ Engl J Med 2003; 349: 776-88.

2. White PC, Speiser PW. Congenital adrenal hyperplasia due to 21-hydroxylase deficiency. Endocr Rev 2000; 21: 24591.

3. White PC, New MI, Dupont B. Congenital adrenal hyperplasia. $N$ Engl J Med 1987; 316: 1580-6.

4. Strachan T. Molecular pathology of congenital adrenal hyperplasia. Clin Endocrinol (Oxf) 1990; 32: 373-93.

5. Bachelot A, Chakthoura Z, Rouxel A, Dulon J, Touraine P. Classical forms of congenital adrenal hyperplasia due to 21-hydroxylase deficiency in adults. Horm Res Paediatr 2008; 69: 203-11.

6. Pang S, Wallace MA, Hofman L, Thuline HC, Dorche C, Lyon IC, et al. Worldwide experience in newborn screening for classical congenital adrenal hyperplasia due to 21hydroxylase deficiency. Pediatrics 1988; 81: 866-74.

7. Krone N, Arlt W. Genetics of congenital adrenal hyperplasia. Best Practice \& Research Clinical Endocrinology \& Metabolism 2009; 23: 181-92.

8. Concolino P, Mello E, Minucci A, Giardina E, Zuppi C,
Toscano V, et al. A new CYP21A1P/CYP21A2 chimeric gene identified in an Italian woman suffering from classical congenital adrenal hyperplasia form. BMC Med Genet 2009; 10: 72 .

9. Witchel SF, Bhamidipati DK, Hoffman EP, Cohen JB. Phenotypic heterogeneity associated with the splicing mutation in congenital adrenal hyperplasia due to 21hydroxylase deficiency. The Journal of Clinical Endocrinology \& Metabolism 1996; 81: 4081-8.

10. White PC, Tusie-Luna MT, New MI, Speiser PW. Mutations in steroid 21-hydroxylase (CYP21). Hum Mutat 1994; 3: 373-8.

11. Higashi Y, Yoshioka H, Yamane M, Gotoh O, FujiiKuriyama Y. Complete nucleotide sequence of two steroid 21-hydroxylase genes tandemly arranged in human chromosome: a pseudogene and a genuine gene. Proceedings of the National Academy of Sciences 1986; 83: 2841-5.

12. Wedell A. Molecular genetics of congenital adrenal hyperplasia (21-hydroxylase deficiency): implications for diagnosis, prognosis and treatment. Acta Paediatr 1998; 87: 159-64.

13. Jayathilaka D, Tennekoon K, de Silva KSH, De Silva S. A pilot study on CYP21 gene deletions among a cohort of Sri Lankan children with congenital adrenal hyperplasia. Ceylon Med J 2017; 62

14. de Silva KSH. Management of 21 hydroxylase deficiency salt-wasting form of congenital adrenal hyperplasia. Sri Lanka Journal of Diabetes Endocrinology and Metabolism 2012; 1.

15. Bruque CD, Delea M, Fernández CS, Orza JV, Taboas M, Buzzalino N, et al. Structure-based activity prediction of CYP21A2 stability variants: A survey of available gene variations. Sci Rep 2016; 6: 39082.

16. Ferenczi A, Garami M, Kiss E, Pék M, Sasvári-Székely Mr, Barta C, et al. Screening for mutations of 21hydroxylase gene in Hungarian patients with congenital adrenal hyperplasia. The Journal of Clinical Endocrinology \& Metabolism 1999; 84: 2369-72.

17. Koyama S, Toyoura T, Saisho S, Shimozawa K, Yata J. Genetic analysis of Japanese patients with 21-hydroxylase deficiency: identification of a patient with a new mutation of a homozygous deletion of adenine at codon 246 and patients without demonstrable mutations within the structural gene for CYP21. The Journal of Clinical Endocrinology \& Metabolism 2002; 87: 2668-73. 
18. Ordoñez-Sánchez ML, Ramírez-Jiménez S, LópezGutierrez AU, Riba L, Gamboa-Cardiel S, Cerrillo-Hinojosa M, et al. Molecular genetic analysis of patients carrying steroid 21-hydroxylase deficiency in the Mexican population: identification of possible new mutations and high prevalence of apparent germ-line mutations. Hum Genet 1998; 102: 170-7.

19. Dain LB, Buzzalino ND, Oneto A, Belli S, Stivel M, Pasqualini T, et al. Classical and nonclassical 21-hydroxylase deficiency: a molecular study of Argentine patients. Clin Endocrinol (Oxf) 2002; 56: 239-45.

20. Forouzanfar K, Seifi M, Hashemi-Gorji F, Karimi V, Estiar M, Karimoei M, et al. Mutation analysis of the CYP21A2 gene in congenital adrenal hyperplasia. Cell Mol Biol 2015; 61: $51-5$.

21. Kharrat M, Tardy Vr, M'rad R, Maazoul F, Jemaa LB, Refai M, et al. Molecular genetic analysis of Tunisian patients with a classic form of 21-hydroxylase deficiency: identification of four novel mutations and high prevalence of Q318X mutation. The Journal of Clinical Endocrinology \& Metabolism 2004; 89: 368-74.

22. Ramazani A, Kahrizi K, Razaghiazar M, Mahdieh N, Koppens $\mathrm{P}$. The frequency of eight common point mutations in CYP21 gene in Iranian patients with congenital adrenal hyperplasia. Iranian Biomedical Journal 2008; 12: 49-53.

23. Khajuria R, Walia R, Bhansali A, Prasad R. The spectrum of CYP21A2 mutations in Congenital Adrenal Hyperplasia in an Indian cohort. Clin Chim Acta 2017; 464: 189-94.

24. Ezquieta B, Oliver A, Gracia R, Gancedo PG. Analysis of steroid 21-hydroxylase gene mutations in the Spanish population. Hum Genet 1995; 96: 198-204.

25. Chiou S-H, Hu M-C, Chung B-C. A missense mutation at Ile172 - Asn or Arg 356 - Trp causes steroid 21hydroxylase deficiency. J Biol Chem 1990; 265: 3549-52. 